\title{
A Propaganda e a Publicidade de MEDICAMENTOS E A INFORMAÇÃO AO CONSUMIDOR
}

\author{
THE PROPAGANDA AND ADVERTISING OF \\ MEDICINES AND THE INFORMATION TO THE CONSUMER
}

Miriam Keiko de S. Sato ${ }^{(*)}$

\section{RESUMO}

As discussões que permeiam este estudo abrangem o problema trazido pela intensa propaganda atualmente feita a respeito do consumo de medicamentos. A análise de um discurso comum sobre a nocividade de produtos farmacêuticos, com seus vagos parâmetros e falta de referências, instigou-nos à busca de parâmetros técnicos e factuais a fim de alcançar uma noção correta a respeito da dimensão de tal problema e, assim, avaliar as circunstâncias sob as quais os medicamentos são introduzidos na vida de cidadãos ordinários por meio da propaganda. Essas circunstâncias são apenas e parcialmente desvendadas por meio do exame das contradições conceituais entre a segurança e a nocividade do medicamento, da comparação do discurso sobre o direito à saúde e à proteção com o discurso, tal qual expresso nas propagandas das drogas, do exame das limitaçōes impostas à propaganda por regulamentos oficiais e considerações de representantes do povo.

\section{Palavras-chave}

Propaganda, Publicidade de Medicamentos, Consumidor.

\section{ABSTRACT}

The discussions which permeate this study do encompass the problem brought by the intense advertising currently made concerning the consumpti-

(") Advogada, Mestre em Direito pela Faculdade de Direito da Universidade de São Paulo. 
on of medicines. The analysis of a common discourse about the harmfulness of pharmaceutical products, with its vague parameters and lack of references, has instigated us to search technical and factual parameters in order to reach a correct notion regarding the dimension of such problem and, thus, evaluate the conditions under which medicines are introduced in the life of ordinary citizens by means of advertising. These conditions are only and partially disclosed through the examination of the contradictory conceptions between safety and harmfulness of the medicine, comparison of the discourse about health right and protection with the discourse as stated in advertisements of drugs, examination of the limitations imposed upon advertising by official regulations and consideration of the popular representations.

\section{Key-words}

Propaganda, Medicine, Advertising, Consumer.

\section{INTRODUÇÃO}

Assistimos a um extraordinário progresso no campo dos medicamentos, notadamente após o intercâmbio científico propiciado pela invenção da imprensa, que favoreceu a difusão dos conhecimentos farmacológicos. Pela primeira vez na história da humanidade, por obra da inteligência do homem, grupos inteiros de causas de morte foram completamente controlados. Os modernos meios terapêuticos modificaram profundamente a nosologia das populações e contribuíram decisivamente ao prolongamento da vida média, chegando a influenciar notavelmente a composição demográfica das populações, com profundos reflexos de ordem política, econômica e social.

O medicamento mereceu assim tratamento diferenciado de produto qualquer encontrado no mercado, porquanto tem por escopo preservar um direito fundamental: o direito à saúde. Para tanto, exige-se-the, como requisitos essenciais, a segurança e a eficácia.

Se por um lado devemos aos medicamentos a melhoria da saúde e 0 aumento da sobrevida da população, por outro lado foram eles causadores de lamentáveis tragédias. Os danos decorrentes dessas tragédias despertaram a consciência jurídica sobre a necessidade de disciplinar toda a cadeia de produção e venda do medicamento que, por sua finalidade profilática, curativa, paliativa ou para fins diagnósticos, tem relevante caráter público, integrando o sistema de assistência a saúde.

Como direito subjetivo, a saúde é consagrada no art. 196 da Carta Magna como "direito de todos e dever do Estado". Na verdade, o direito à 
vida, à saúde, não estão apenas erigidos à categoria de direitos fundamentais, recebendo portanto a tutela constitucional, como também inserem-se na lei ordinária. Os medicamentos, enquanto importante meio para promoção, manutenção e recuperação da saúde, adquirem relevância pública e, como tal, inserem-se entre as ações e serviços de saúde sujeitos a regulamentação, fiscalização e controle do Poder Público (art. 197 da CF), em toda a sua cadeia de produção. Estaremos abordando aqui uma etapa específica dessa cadeia, qual seja, a publicidade do medicamento.

\section{A PUBLICIDADE E PROPAGANDA}

O tema abordado tem seu próprio mérito e atualidade, e pretendemos oferecer nossa modesta contribuição, trazendo à tona questões nascidas do vertiginoso progresso da ciência farmacêutica, ao lado do desenvolvimento não menos espantoso das técnicas de publicidade.

Assim, as discussões que permeiam este estudo giram em torno do problema da intensa publicidade que hoje se faz para o consumo de medicamentos. As drogas afetam e alteram a saúde e, pelas suas propriedades, ocupam papel proeminente na sociedade. Por outro lado, a vulnerabilidade dos doentes conduziu à criação de uma extensa rede de dispositivos regulamentadores para proteção do consumidor.

Pareceu-nos inevitável fosse o rumo de nosso trabalho, atraído à análise do discurso publicitário de produtos terapêuticos inserido na história social, em cujo contexto se confundem a evolução científica, o desenvolvimento de novas técnicas de propaganda e a questão jurídico-social da saúde.

Esta história revela-nos que a preservação da saúde ganhou contornos fortemente econômicos na sociedade industrial. A produção em massa e em série inseriu entre o fabricante e o consumidor extensa cadeia de serviços, entre os quais a venda da imagem e a publicidade.

Este aliás é o movimento resultante de um febril processo de mudanças nos campos social e econômico. Com iniciativas para a desregulamentação da economia e de derrubada da muralha da proteção aduaneira, o Poder Público veio dar maior dimensão à competição, que é um dos traços identificadores da economia de mercado(1).

Doravante, com o acirramento da concorrência, qualquer empresário precisa organizar-se segundo os moldes mais modernos para integrar-se no sistema econômico atual, no qual é permanente a necessidade de atender às exigências do consumo.

(1) CENEVIVA, Walter. Publicidade e Direito do Consumidor. São Paulo: RT, 1991. 
Nessa perspectiva, é claro que as novas exigências da conjuntura criam para as pesquisas necessidades várias, notadamente aquelas que dizem respeito à estrutura das suas relações com o mercado, com os consumidores, hoje quase que totalmente atreladas à publicidade e ao marketing(2).

Da mesma forma, nesta esteira de mudanças, o sistema legal pátrio procura adequar-se, em especial no que tange à reparação dos danos resultantes dos maus produtos e serviços.

É certo que nosso Código Penal, com meio século de existência, já prevê figuras delituosas no tocante à saúde pública e à economia popular. Posteriormente, a Lei n. 1.521/51 cuidou dos abusos de preços e da adulteração de remédios, gêneros alimentícios etc. Mas afigura-se-nos que a proteção ao comprador só se converteu em um dos objetivos da política oficial depois que a economia do País atingiu determinado grau de desenvolvimento.

Quando a economia do Brasil se classificava em oitavo lugar em face das demais nações, o legislador tratou de amparar o consumidor. Em $1^{\circ}$ de setembro de 1990, o Presidente da República sancionou a Lei n. 8.078, que se tornou conhecida como Código de Defesa do Consumidor.

O nosso Código de Defesa do Consumidor abrigou em seu texto os quatro direitos fundamentais do consumidor estabelecidos pela Comissão das Nações Unidas sobre os direitos do homem, em sessão realizada em 1973, em Genebra, direitos que são os seguintes: o direito à segurança; o de ser adequadamente informado sobre os produtos e os serviços, bem como sobre as condições de venda; o direito de escolher entre bens alternativos de qualidade satisfatória a preços razoáveis; e o direito de ser ouvido no processo de decisão governamenta|(3).

Reza o artigo $6^{\circ}$, inciso III, do Código de Defesa do Consumidor que 0 comprador deve ter "informação adequada e clara sobre os diferentes produtos e serviços, com especificação correta de quantidade, características, composição, qualidade e preço, bem como sobre os riscos que apresentem". 0 empresário-vendedor que omitir tais informações está sujeito à ação judicial, para reparação de danos sofridos pelo comprador.

O inciso IV desse mesmo artigo protege o consumidor contra a publicidade enganosa e abusiva, métodos comerciais coercitivos ou desleais, bem como contra práticas e cláusulas abusivas ou impostas no fornecimento de produtos ou serviços. Preocupam-nos essas práticas na publicidade de medicamentos.

(2) CABRAL, Plínio. Propaganda - Técnica da Comunicação Industrial e Comercial. São Paulo: Saraiva, 1993.

(3) COMPARATO, Fábio Konder. Estudos e Pareceres de Direito Empresarial. Rio de Janeiro: Forense, 1999, p. 477. 
A publicidade de medicamentos é feita de muitas maneiras, mediante o uso de recursos que incluem a televisão, jornais, revistas, folhetos, rádio, Internet e vendedores. Pretende-se com a Lei impedir que sejam esses meios de comunicação usados para, mediante artifícios, esconder os vícios e defeitos de um produto ou omitir seus maleficios.

Todavia, mais que isso, a publicidade procura influenciar a opinião dos membros da coletividade, conduzindo-os a um pensamento ou uma conduta, como, por exemplo, comprar determinado bem ou comportar-se desta ou daquela maneira, induzido pela publicidade ${ }^{(4)}$.

Indaga-se quais os efeitos desta revolução tecnológica na publicidade sobre um grande grupo de consumidores, o qual atrai fortemente o interesse das indústrias farmacêuticas.

Os medicamentos são oferecidos no mercado por meio de fortes técnicas de indução. Mesmo com a existência de normas que regulamentam sua publicidade, parece-nos inescapável perceber os efeitos nocivos dessa prática em relação aos medicamentos que, sem qualquer parcimônia, foram inseridos num mercado de consumo em massa.

Não se pode perder de vista, porém, que o medicamento, por ser produto essencial à vida, à saúde, não pode ser reduzido à mercadoria, em que pese a realidade aponte para sua transformação em bem de consumo qualquer. O medicamento integra o sistema de assistência à saúde e, como tal, deve ter toda a sua cadeia produtiva, incluindo-se a divulgação e comercialização, rigorosamente regulamentada e fiscalizada.

\section{A OBRIGAÇÃO DE INFORMAR}

Há muito tempo se conhece o risco dos medicamentos quanto aos danos que podem causar ${ }^{(5)}$. A ocorrência de diversos surtos epidêmicos de efeitos adversos graves ${ }^{(6)}$ levou os governos de muitos países a desen-

(4) CABRAL, Plinio. Op. cit., 1993.

(5) Galeno defendia a idéia de que todo medicamento pode transformar-se em veneno. No ano de 1785, Wighering elaborou uma das primeiras descriçōes de uma reação adversa, na qual discorreu, de forma abrangente, a respeito da intoxicação digitálica. As investigaçōes nesse sentido prosseguiram, sendo que, em 1880 , foram realizadas pesquisas em casos suspeitos de reações adversas. Os casos em estudo eram de pacientes que vieram a óbito após terem recebido anestesia por clorofórmio. Em 1922, foram estudados casos em que os pacientes desenvolveram ictericia após terem sido submetidos a um tratamento contra a sifilis (BARROS, José Augusto Cabral de. Propaganda de Medicamentos: Atentado à Saúde? São Paulo: Hucitec, 1997, p. 31).

(6) Como exemplos desses surtos, podem ser citados: as 107 mortes que aconteceram nos Estados Unidos, em 1937, em decorréncia do uso do dietilenoglicol, num xarope; na França, em 1954, aconteceram 100 mortes devido ao uso de um medicamento destinado ao tratamento da furunculose e que apresentava estanho em sua composição (DAVIES, D. M. Textbook of adverse reactions. 4th edition. Oxford: Oxford University Press, 1991); no Japảo, na década de 50, ocorreram 
volver um sistema que thes permitisse vigiar a segurança no uso de fármacos.

Nas últimas décadas, a farmacoepidemiologia e a farmacovigilância foram grandemente desenvolvidas. Contudo, esse progresso não foi suficiente para conter determinados casos resultantes de reações adversas que demoraram muitos anos para serem associados ao uso de medicamentos ${ }^{(7)}$. Assim, ainda que não tenha o condão de solucionar tal quadro, tornou-se cada vez mais premente a atuação preventiva, que se apóia fundamentalmente na obrigação do fabricante de informar aos profissionais da saúde e aos pacientes sobre os riscos do medicamento, não somente nas bulas como também nas peças publicitárias, desde seu lançamento às atualizações necessárias durante sua comercialização.

Nessa esteira, a Secretaria de Vigilância Sanitária do Ministério da Saúde estabeleceu, por meio da Portaria n. 802, de 8 de outubro de 1998, a obrigação da empresa fabricante de fazer constar das embalagens e bulas as informações essenciais à segurança dos produtos farmacêuticos.

Nessa mesma direção, porém disciplinando especificamente as bulas, surge a Portaria n. 110, de 10.3.2000, por meio da qual procurou a Agência Nacional de Vigilância Sanitária instituir roteiro para texto de bula de medicamentos com a finalidade de orientar adequadamente o paciente e o médico. Essa Portaria foi sucedida pela Resolução-RDC n. 140, de 29.5.2003, da ANVISA, a qual manteve a redação em sua essência.

Importante ressaltar que a literatura médica já lecionava que os argumentos usados nos anúncios dos medicamentos não podem se afastar das

diversos casos de perda da visāo, paralisia e morte associados ao uso do clioquinol; na Austrália, Nova Zelåndia, Pais de Gales, Escócia e Irlanda, durante os anos 60, muitas mortes foram atribuidas ao uso do fármaco isoprenalina, que era usado em crises de asma (TAYLOR, R. Medicine out of Control - the anatomy of a malignant technology. Melbourne: Sun Books, 1979). Um dos casos de maior repercussāo mundial, foi o triste episódio da talidomida, que era usada como um hipnosedante. Aparentemente a droga não produzia efeitos indesejáveis, porém, quando consumida por mulheres gestantes, causava má-formaçāo congénita nos nascituros, denominada focomelia. $\mathrm{Na}$ época em que esse medicamento começou a ser utilizado (anos 60), a focomelia era pouco conhecida, pois era bastante rara. Contudo, após iniciar-se o uso da talidomida, ocorreu um surto dessa má-formação e mais de 498 mortes (DAVIES, D. M. - Obra cit. Nos Estados Unidos, no ano de 1960 , teve inicio uma série de programas de vigiláncia em hospitais, baseados em dados de reaçōes adversas coletados).

(7) Como exemplo dessas situações, cita-se a aminopirina; somente após 47 anos de uso no mercado é que se descobriu que apresenta toxicidade para a medula óssea. Outros exemplos de casos em que se passaram longos periodos até que o medicamento tosse associado a uma reação adversa são o do cincofeno, que demorou 15 anos para ser relacionado à ictericia decorrente de seu uso; e o do ácido acetil-salicilico, o qual, passados 39 anos de seu uso, veio a ser objeto de estudos para verificar sua relação com casos de hemorragias digestivas, e ainda outros 20 anos até que esse efeito adverso do ácido acetil-salicílico tosse conhecido de maneira mais ampla (DAVIES, D. M. - Obra cit.). 
informações contidas na bula ${ }^{(8)}$. Aliás, as informações contidas na bula são tão importantes que seu texto, no que é essencial, deve estar impresso nos anúncios de medicamentos, como veremos a seguir.

A Resolução-RDC n. 140 divide tais informações, fundamentais ao uso do medicamento, basicamente em três grupos:

a) identificação do produto (nome comercial; denominação genérica dos princípios ativos; uso pediátrico ou adulto; composição etc.);

b) informação ao paciente (em linguagem acessivel, deve obrigatoriamente informar a ação do medicamento, indicações e contra-indicações, advertências, precauções, interações medicamentosas, reações adversas, posologia, condutas na hipótese de superdosagem, cuidados de conservação);

c) informação técnica (características químicas e farmacológicas; resultados de eficácia; doses máximas e duração do tratamento; ajustes de doses para idosos, crianças e outros grupos de risco; advertências sobre medicamentos novos etc.).

Essas mesmas informações acima são exigidas também pela Resolução RDC n. 102, de 30.11.2000, que determina sua inclusão nas propagandas, mensagens publicitárias e promocionais de medicamentos. Destarte, tocias as bulas, prospectos, textos e quaisquer materiais de divulgação e informação médica ou publicitária deverão ostentar as advertências e reações adversas do medicamento( ${ }^{(9)}$. Justifica-se essa obrigação pelo fato de que as substâncias medicamentosas podem causar uma grande variedade de efeitos indesejáveis ao organismo.

Por mais trivial que seja a ação terapêutica de um medicamento, sempre existe o risco de que cause algum malefício ao paciente que o usa. Os órgãos responsáveis pela segurança dos medicamentos comercializados não conseguem evidentemente conferir segurança absoluta ao medicamento(10). $\mathrm{Na}$ realidade, tanto a indústria farmacêutica como os profissionais de saúde procuram avaliar se o benefício proporcionado por um fármaco é superior aos riscos potenciais que apresenta. Em tais condições, difícil concluir com exatidão o resultado do "equilíbrio" desses dois fatores.

(8) NIES, Alan S. "Principios da Terapéutica". In: GOODMAN \& GILMAN, Alfred et al. As Bases Farmacológicas da Terapêtica. $8^{9}$ ed. Rio de Janeiro: Guanabara Koogan, 1991, p. 49.

(9) Reação adversa a medicamento é a "resposta a um produto farmacêutico que é nociva e não intencional e que ocorre em doses normalmente utilizadas para profilaxia, diagnóstico ou tratamento de doenças ou para a modificação de uma funçāo fisiológica (OMS)". SINDICATO DA INDU்STRIA DE PRODUTOS FARMACÉUTICOS NO ESTADO DE SĀO PAULO, Farmacovigilância Manual de Implementação, p. 3.

(10) NIES, Alan S. Ob. cit., p. 49. 
Forte exemplo do equilibrio desconhecido verifica-se no lançamento do medicamento novo. Nesse sentido, a Resolução-RDC n. 140/2003 estabelece, na parte que trata das informações técnicas, mais precisamente em seu artigo $2^{\circ}$, inciso III, item 10, que, quando se tratar de produto novo, deverão ser acrescentados na bula, durante 5 anos, os seguintes dizeres: "Atenção: este é um novo medicamento e, embora as pesquisas tenham indicado eficácia e segurança aceitáveis para comercialização, efeitos indesejáveis e não conhecidos podem ocorrer. Neste caso, informe seu médico".

Ora, o texto acima, que a Secretaria de Vigilância Sanitária do Ministério da Saúde tornou obrigatório, revela com todas as letras uma realidade inescapável no que tange ao novo medicamento, qual seja: não existe como avaliar com precisão os efeitos adversos que ele pode causar antes de ser colocado no comércio. Argumenta-se que, somente após o início da comercialização de um medicamento, quando maior número de pessoas fica exposta a ele, é que podem ser aplicados os métodos complementares de observação de ocorrência de efeitos indesejáveis raros ou inesperados, pois a população exposta ao fármaco é maior e mais heterogênea que a população estudada em ensaios clínicos anteriores à comercialização.

Nessas condições, é razoável e recomendável que os médicos desenvolvam seu convencimento e raciocínio sobre determinado medicamento, considerando, em primeiro plano, o seu princípio ativo, e não o seu valor comercial ou a retórica publicitária.

Contudo, não podemos olvidar que tanto os médicos como os consumidores são assediados por propagandas massivas de medicamentos, cujas técnicas se desenvolvem forte e rapidamente, em detrimento de uma campanha educativa ou de esclarecimentos a permitir ao consumidor e aos próprios profissionais da saúde ter acesso às informações completas e essenciais aqui sucintamente descritas. Tais técnicas de persuasão, cada vez mais sofisticadas, desafiam especialistas e as legislações que objetivaram o seu controle.

\section{A ESTRATÉGIA PUBLICITÁRIA}

Se há um discurso pouco estudado pelos historiadores ou pesquisadores em ciências humanas, é o anúncio publicitário; no entanto, muito rico em informações de ordem econômica, social e ideológica. De fato, é curioso que, até o momento, temos subestimado um discurso publicitário revelador dos imaginários sociais. Sabe-se que todo discurso publicitárıo tem uma finalidade precisa: promover a venda de um produto. Esta se faz por diversos meios. Utiliza-se de tal discurso para seduzir ou atrair a atenção do consu- 
midor eventual, aproximando-o o máximo possivel de componentes de seu ambiente cultural ou ideológico.

Da análise da publicidade é possível perceber o que prevalece na representação ou no imaginário. Verificamos que são os problemas relacionados aos cuidados com o corpo, mais particularmente à doença, que dominam a publicidade escrita das primeiras décadas do século $X X$. Paralelamente ao desenvolvimento das ciências médicas e expansão da imprensa, assistimos a um mundo onde a vida física e os cuidados com a saúde tornam-se uma preocupação crescente. Neste contexto, a publicidade dos medicamentos, associados à manutenção e à terapêutica do corpo, adquirem legitimidade e bases novas. Afigura-se-nos relevante evidenciar os traços mais reveladores.

A linguagem publicitária contém duas perspectivas funcionais principais, que constituem o ponto de articulação onde se realizará o que Jean Baudrillard chamou de "efeito publicitário"(11), ou seja, a incitação à compra de um produto. São elas a necessidade e o desejo. No começo do século $X X$, estruturou-se uma concepção de corpo como força produtiva ligada quase que exclusivamente à necessidade. O corpo passou a ser sinônimo de "valor de uso", vantagem sobre o valor de troca; assim ele foi explorado na publicidade moderna.

Sempre foi significativa a primeira função dos medicamentos, qual seja, a cura da doença, uma vez que assim dá ao corpo a força do trabalho. Mas somente a partir da metade do século XX é que nos aproximamos da promoção hedonista da valorização do corpo sadio. Surgiu a publicidade-sedução, que, invadindo a mídia, ensejou a criação publicitária inspirada nos sistemas culturais. Ela inseriu sobre os valores mais susceptiveis a vontade da compra, a qual foi empregada na publicidade dos medicamentos no começo do século XX. Não se podia pensar o corpo, na estratégia publicitária, diversamente de sua definição cultural e condição social.

O discurso publicitário da época soube se apropriar das representações dos meios populares em face da doença, para definir um discurso sobre os cuidados com a saúde. Este se aproximou para somar a relação à necessidade. Destarte, a necessidade de medicação, então ocasionada primeiramente pela doença, passa a ser, nessa produção simbólica, gerada pelos produtores da necessidade desses bens. A publicidade farmacêutica considerou as inquietudes e angústias que causavam algumas doenças ou mal-estar. Os publicitários apostaram nas classes populares por razões

(11) BAUDRILLARD, Jean. La societé de consommation. Paris: SGPP, 1970, p. 196. Para Baudrillard, o corpo é significante por excelência; nele se inscrevem os valores e ideologias: "Le mode d'organisation de la relation au corps reflète le mode d'organisation de la relation aux choses et celui des relations sociales". 
evidentes de mercado. Mas Baudrillard cogita que tal estratégia pode ter servido também para "explorar" a crença das pessoas não munidas intelectual e materialmente ${ }^{(12)}$.

Se, por um lado, velhas crenças e numerosos preconceitos não foram desprezados, paralelamente, o discurso da publicidade se autorizava da ciência médica e das descobertas da pesquisa científica. Esse sincretismo de saberes organizados (médico-bioquímico), de crenças e de mitos não é estranho, sobretudo se nós admitirmos que os conhecimentos não são sempre de verdades científicas, nem mesmo de conhecimentos estanques. É difícil, porém, estabelecer o que, nesses mitos, é de ordem da estratégia de promoção da venda e o que é reconhecido ingenuamente como verdade. De toda sorte, as representações utilizadas na época mostram bem que a retórica publicitária não é nem mais nem menos fundada em certos discursos cientificos: utiliza-se de um discurso popular para tornar o produto mais atraente e um discurso pseudocientífico moral, para convencer.

As estratégias e a uniformização das publicações farmacêuticas eram pontuadas de elementos que tinham conotação estreita com a ideologia produtivista. Outra evidência de curar a doença, a função primeira dos medicamentos, é de doar ao corpo o poder do trabalho. $O$ que se pode dizer senão que tal funcionalidade mantém relações estreitas com modelos culturais tradicionais? Sob o culto da eficácia terapêutica, o discurso publicitário teve de submeter-se a uma representação mais ampla possivel, para atingir sua principal finalidade: incitar o leitor a consumir o produto.

Com efeito, a publicidade farmacêutica se desenvolveu, então, por séculos, trazendo em si uma dimensão econômica e ideológica crescente ${ }^{(13)}$. A adoção do discurso do corpo sadio e produtor, verdadeiro fenômeno social, envolvia valores e um público-alvo, cujo imaginário inspirou o que poderia chamar certa política do corpo, quer dizer, a composiçāo de uma ordem. Ao propiciar a venda do produto, o corpo doente tornou-se, de alguma forma, um valor sobre o qual há geração de riquezas. Promover a venda de produtos farmacêuticos implica ter certa imagem do corpo a manter, uma imagem que se articula em torno de certo número de representações. Toda mensagem publicitária, seja atual, seja antiga, contém um fim mercantil(14). A publicidade de medicamentos não é exceção.

A doença foi também submetida a um tratamento discursivo. Nós a representamos de forma a valorizar certos aspectos em detrimento de ou-

(12) Ibidem.

(13) Ibidem.

(14) BITTAR, Carlos Alberto. O controle da publicidade no Código de Defesa do Consumidor Sancionamento a mensagens enganosas $\theta$ abusivas. Såo Paulo: Revista dos Tribunais, n. 673 , novembro/1991, p. 7. 
tros. Por exemplo, a maioria dos anúncios publicitários acentua o aspecto psicológico da representação do corpo (medo da doença), em detrimento de uma precisão científica. A doença é submetida a um tratamento ideológico que põe em evidência as relações entre os tipos de desordem invocados e o contexto de uma sociedade mais vulnerável pela doença e morte do que é realmente.

O mister da criação publicitária é a valorização do produto(15). E o discurso publicitário, sendo por natureza mercantil, será necessariamente parcial. A partir dele temos um número expressivo de desordens que serão combatidas pelo poder do remédio. Trata-se de uma estratégia simples, na qual, quanto maior o espectro de doenças tratadas pelo remédio, mais chances ele terá de encontrar um consumidor. Resulta dessa publicidade, ao final do século $\mathrm{XX}$, a idéia de que os medicamentos são capazes de curar tudo ou quase tudo. E eles são numerosos, alguns até mesmo curiosos por suas composições enigmáticas. Suas classificações não são claras, tampouco as informações concernentes aos componentes. Importa que as numerosas ameaças de doenças respondem aos mais variados medicamentos, isto é, haverá sempre mais produtos que doenças.

É necessário, por outro lado, considerar o resultado inerente a toda publicidade: promover a venda de um produto. Nessa esteira, o papel dos publicitários é o de convencer o consumidor. Não se trata de concluir um juizo de valor sobre suas intenções e sua honestidade, mas sim compreender o processo de indução. Sem dúvida, seria necessário dar aos produtos uma imagem concreta e convincente, apresentá-los segundo suas caracteristicas mais atraentes, a fim de persuadir o consumidor de que a cura compensa a despesa ocasional. A arte da cura tornou-se, dentro desse contexto, algo que $o$ anúncio publicitário reduziu à dimensão mercantil.

\section{A REPRESENTAÇÃo DA SAÚdE}

O setor farmacêutico, como qualquer setor empresarial, estimula o consumo de seus produtos por meio das campanhas publicitárias. Nesse contexto, interessa a ocorrência de um máximo de doenças acompanhadas de um máximo de tratamentos. Ocorre, assim, um fenômeno no qual se verifica o crescimento da intervenção da medicina na vida das pessoas, passando para alçada médica problemas determinados pela forma de ser da sociedade, ou seja, problemas que, mesmo tendo origem natural ou fisiológica, crescentemente passaram a ser merecedores de intervenção médica.

(15) SMITH, MICKEY C. Ph.D. Pharmaceutical Marketing. New York: The Haworth Press, 1991. 
Da mesma maneira que o acesso ao consumo tornou-se o principal meio para atingir o bem-estar e a felicidade, o acesso às tecnologias modernas de diagnóstico e terapia passaram a ser condição necessária à saúde. $A$ eficácia dessas tecnologias está diretamente vinculada aos avanços tecnológicos alcançados.

O consumo intenso e a grande dependência de serviços e bens de natureza médico-assistencial vêm caracterizando a sociedade moderna. Esse quadro gera um progressivo consumo de intervenções médicas, diante de sintomas que nem sempre são classificados como enfermidades ${ }^{(16)}$. Para alguns pesquisadores trata-se de uma "transformação em doença"(17), que vem a agravar o nível de dependência aos medicamentos

Verifica-se, no contexto em que os medicamentos são lançados, que a eles foram atribuídas funções que ultrapassam sua ação farmacológica. $O$ sinal mais ilustrativo da função simbólica do medicamento é o fato de que, para o paciente, a boa consulta médica deve ser acompanhada de prescrição. Para o médico, por seu turno, a inovação integra sua competência, donde passa a prescrever o produto novo lançado no mercado(18).

Cresce o número de pessoas que passaram a acreditar que seus probleinas podem ser resolvidos com o uso dos serviços oferecidos pelos sistemas de saúde, independentemente de esses problemas serem ou não de ordem médica. Como conseqüência, o papel da medicina e dos instrumentos tecnológicos de que ela dispõe foram enaltecidos. Com isso, ocorreu também uma diminuição da capacidade das pessoas de buscar soluções alternativas para seus males, especialmente quando acreditam serem problemas de caráter médico ${ }^{(19)}$.

Argumentos apresentados pela indústria moderna para enfatizar a necessidade do uso intensivo das novas e supostamente mais eficazes técnicas diagnósticas e terapêuticas vêm sendo postos em questão, especialmente no âmbito dos medicamentos. Entende-se restrita a visão da etiologia e do tratamento, a qual reflete, na prática, nos meios de comunicação ao difundir os medicamento. Essa questão é bem examinada por Temporão(20), ao acentuar que a publicidade conduz à idéia de que o próprio corpo é o

(16) BARROS, José A. C. "Tranquilizantes benzodiazepinicos: ¿Instrumento de Cura o de Medicalización?", Cuad. Med. Soc. (Ros) (68):67-73.

(17) TAYLOR, R. Medicine out of Control - the anatomy of a malignant tecnology. Melbourne: Sun Books, 1979.

(18) BARROS, J. A. C. Medicalización y salud, 1984, Cuad. Med. Soc. (Ros) (28):25-31.

(19) Houve $O$ abandono de outras possibilidades terapêuticas relacionadas à utilização dos potenciais orgânicos e psicológicos do próprio paciente (MEDAWAR, C. "Power and dependence social audit on the safety of medicines". Londres: Social Audit., 1992).

(20) TEMPORĀO. José G. A propaganda dos medicamentos e o mito da saúde. Rio de Janeiro: Graal, 1986. 
responsável pelo aparecimento das doenças, e que a solução dos males pode ser alcançada com o uso de medicamentos; essa idéia exclui das causas de doenças a influência dos fatores relacionados às condições de vida das pessoas.

Esse paradigma, contudo, tem-se mostrado ineficiente para conceituar ou dar respostas efetivas às moléstias atuais (doenças degenerativas). Acrescente-se, ainda, o fato de que os custos crescentes envolvidos na medicina atual (proliferação de especialidades, exames de laboratórios, inúmeras "soluções químicas" etc.) (21) são muito elevados, confrontando-se, portanto, com as propostas de democratização dos serviços de saúde, principalmente nos países subdesenvolvidos.

Em que pesem os limites propostos por este estudo, não poderíamos deixar de abordar rapidamente alguns dos importantes fatores que influem na publicidade e consumo dos medicamentos, em cujo contexto predomina a lógica do modo de produção capitalista, como o faz Giovannit22):

"(...) enquanto a ampliação da produção é uma lei de bronze do modo de produção capitalista, conseqüência ao mesmo tempo que condição da busca incansável do lucro máximo, a extensão da demanda solvente em geral e da demanda de produtos fabricados em particular, não cai em absoluto sob o âmbito desta lei. Pelo contrário, a extensão da demanda solvente é o problema que o capitalismo está obrigado a resolver para poder realizar a ampliação da produção. É esta contradição, lei essencial da acumulação capitalista, entre a capacidade - ilimitada - de produzir e a - limitada - de consumir que, em definitivo, empurra o capitalismo a ampliar seus mercados e, em conseqüência, a criar constantemente novas necessidades de consumo".

Considerando o argumento de Giovanni, a ideologia do consumo desempenha papel fundamental para escamotear tal contradição. Note-se que o autor enxerga o consumo como uma relação democrática, onde o indivíduo pode escolher se vai ou não consumir determinado bem, e, pelo menos teoricamente, essa escolha independe do modo como a produção e a distribuição do bem estão estruturadas. Em outras palavras, a ideologia do consumo estaria, dessa forma, minimizando a contradição entre a "capacidade ilimitada de produzir" e a "capacidade limitada de consumir".

Neste contexto é que se descortina para o consumidor um mercado no qual deixam de existir a liberdade de opção e o conhecimento real quanto à

(21) QUEIROZ, M. S. O paradigma mecanicista da medicina ocidental: uma perspectiva antropológica. Rev. Saúde Pública, 20:309-17, 1986.

(22) GIOVANNI, G. A questão dos remédios no Brasil - produção e consumo. Coleção Sociologia e Saúde. São Paulo: Polis, 1980. 
qualidade ou à necessidade efetiva do que se consome. Assim é que o nível de "bem-estar"(23) seria resultado da possibilidade de acesso, pelo conjunto de indivíduos, das conquistas técnico-científicas. Contudo, é importante que se alcance um equilibrio entre o consumo exagerado e o consumo mínimo ou inexistente por determinados indivíduos. O contínuo surgimento de novas necessidades, ou seja, de novos bens para consumir, somado ao problema da desigualdade marcante na repartição da renda, comprometem o poder de aquisição de expressivos segmentos da sociedade.

Tem-se, segundo Rozenfield(24), como principais conseqüências do consumo exagerado e acrítico, o incentivo à obtenção de bens pelo sistema de crédito; a substituição da valorização do ser pela valorização do ter, a ocorrência de distorções ou inversões (como a aquisição de bens desnecessários ou a contratação pelos governos de serviços de infra-estrutura destinados a grupos sociais economicamente privilegiados, em detrimento de outros setores sociais mais carentes); e, finalmente, a destruição do meio ambiente.

Esse consumo acrítico e irracional é alimentado continuamente pelas massivas investidas das campanhas publicitárias, prática extremamente danosa no campo da saúde. Essa realidade é que deve ser enfrentada pelas autoridades sanitárias. Ao lado do avanço tecnológico das ciências biomédica e farmacêutica, assistimos ao desenvolvimento das técnicas de publicidade cada vez mais sofisticadas e eficientes, atingindo, assim, número crescente de consumidores. Tais técnicas, que escapam à vigilância dos órgãos públicos, serão mais bem examinadas adiante.

\section{AS TÉCNICAS DE PUBLICIDADE}

O notável crescimento da indústria farmacêutica tem relação direta com os fortes investimentos realizados em publicidade ${ }^{(25)}$. Uma das conse-

(23) BENJAMIN, Antonio H. V. "Uma Introdução ao Código de Defesa do Consumidor". InLAZZARINI M..; RIOS J. O. \& NUNES JR.V. S. Código de Defesa do Consumidor - anotado e exemplificado pelo IDEC. São Paulo: AVS, pp. 9-13.

(24) ROZENFELD, S. \& PORTO, M. A. T. "Vigilância Sanitária: uma abordagem ecológica da tecnologia em saúden. In: Saude, ambiente e desenvolvimento. Rio de Janeiro: Hucitec/Abrasco, pp. 171-96.

(25) No Brasil, no ano de 1980 , produtores de medicamentos declararam que $18,5 \%$ do faturamento das empresas era investido em publicidade; a maior parte desse montante $(13,3 \%)$ era destinada aos gastos efetuados com propagandistas, isto é, vendedores treinados para divulgaçảo dos medicamentos diretamente aos profissionais da saúde (COMISSÃO PARLAMENTAR DE INQUÉRITO DA INDÚSTRIA FARMACÉUTICA - 1980, Diário do Congresso Nacional, Seção I, Suplemento ao n. 139, 11 novembro, 744 p.). No Reino Unido, segundo pesquisa realizada em $1983,55 \%$ das verbas promocionais das indústrias estavam voltadas para os propagandistas (Effectiveness of UK pharma reps. Scrip (1.596):4, march 6, 1991). Outros estudos no mesmo pais confirmam que a faixa de investimentos aplicada em propagandistas, encontra-se na ordem de $50 \%$ do total das verbas promocionais disponiveis (MACKOWIAK J. I. \& GAGNON/J. P. Effects of promotion on 
qüências negativas desses altos investimentos em publicidade é a elevação do preço final do produto ao consumidor ${ }^{(26)}$. Há estudos que demonstram que os investimentos referidos alcançam duas ou três vezes os investimentos feitos em pesquisas e desenvolvimento de novos fármacos ${ }^{(27)}$. Quanto às promoções dirigidas aos médicos, a média de investimentos em vários países é da ordem de 3 a 8 mil dólares por profissional|(28).

Temos hoje a empresa farmacêutica determinando as características e as necessidades do médico e do paciente, jungida que está à lógica da produção na sociedade de consumo e à sua veiculação publicitária com vistas no lucro(29), por mais que se apregoe a cura, a recuperação do paciente ou seu bem-estar.

Essas eficientes técnicas de publicidade foram desenvolvidas para diferentes públicos, cada qual envolvendo formas específicas de abordagem. Podemos dividir a publicidade de medicamentos em três grupos: aquela direcionada às farmácias; outra endereçada aos profissionais da área de saúde; e, finalmente, a publicidade direta ao consumidor, esta voltada aos medicamentos de venda livre. Essas técnicas de publicidade foram objeto de estudo, em dissertação de mestrado ${ }^{(30)}$, mas não se justificaria aqui aprofundarmo-nos em suas características. Faremos apenas uma rápida explanação de cada uma das modalidades acima.

\subsection{Propaganda de medicamentos em farmácias}

Os estabelecimentos farmacêuticos e, posteriormente, as drogarias sofreram reformulações, dando lugar à estrutura de produção. A farmácia passou, então, a atender interesses puramente comerciais, onde a presença

pharmaceutical demand. Social Science \& Medicine. 20(11):1,191-7, 1985). Considerando que o valor das vendas chegou a 100 bilhões de dólares em 1987, calcula-se que 25 bilhões de dólares corresponderiam a gastos em atividades promocionais (SZUBA T. J. Drug promotion under the magnifying glass. J. soc. Adm. Pharm. 4 (2):77-80, 1987). As empresas farmacêuticas norte-americanas gastaram mais de 917 milhões de dólares no ano de 1997, na publicidade de medicamentos para o consumidor, o que significa um aumento de 46\% em comparação com 1996. Só em 1995 foram gastos nos Estados Unidos mais de 350 milhöes de dólares em propaganda direta ao consumidor de medicamentos para venda com receita médica (Consumer ads Build awareness but not understanding of advertised meciations, survey reveal. American Journal of Health-System Pharmacist, vol. 55, Nov. 15 1998, p. 2344).

(26) LEXCHIN J., Doctors and detailers: Therapeutic education or pharmaceutical promotion? Int. J. Health Serv. 19(4):663-79, 1989.

(27) GEREZ, J. C. Indústria farmacêutica: histórico, mercado e competiçảo. Ciência Hoje. 15 (69):2130/Drug Promotion: stealth, wealth and safety. Lancet, 341:1,507-8, 1993.

(28) HAl (Health Action International) (1992), Promoting health or purshing drugs? A critical examination of marketing of pharmaceuticals. Amsterdam, HAl Europe.

(29) SMITH, Mickey C. Ph.D. Op. cit.

(30) SATO, Miriam Keiko de Souza. Propaganda e Publicidade de Medicamentos no Direito Civil

(Dissertaçāo de Mestrado) - USP/2002. 
do farmacêutico é observada apenas para o cumprimento da Lei n. 5.991/ 73. Essa mesma lei contribuiu fortemente para a formação desse quadro, no qual o medicamento é tratado como mercadoria a ser revendida nos balcões. $E$, em conseqüência, a saúde popular acaba por ser relegada a segundo plano.

É nesse novo contexto que a publicidade alcança proprietários de farmácias e balconistas. Muitas indústrias farmacêuticas partem para técnicas promocionais que consistem na divulgação de seus produtos ao consumidor, especialmente os de venda livre, utilizando-se de incentivos à venda, tais como descontos fornecidos às drogarias. Em relação aos medicamentos de venda sob prescrição, esses laboratórios apóiam-se no papel quase mediador dos balconistas, os quais se tornaram agentes responsáveis pela ampliação das vendas. É comum que as informações obtidas pelos funcionários de farmácia sejam fornecidas pela própria indústria farmacêutica(31).

Surge, então, um novo comércio, que se baseia na persuasão por meio da qual o atendente passa a indicar o maior número de medicamentos possível, o que lhe renderá premiação pela boa venda(32). Essa prática fomenta, contudo, o consumo desmedido de medicamentos, agravado pela ausência de cuidados em relação à prescrição médica ${ }^{(33)}$.

Problemas surgem com a prática ilegal dos balconistas de prescrever o medicamento, cujo despreparo é evidenciado em diversas pesquisas ${ }^{(34)}$. Foi constatado, ainda, que, em 24 estabelecimentos, não existe controle de prazo de validade dos medicamentos e que um percentual muito baixo dos vendedores entrevistados por bairro afirmou ter conhecimento dos efeitos indesejados dos medicamentos comercializados. Tais fatos trazem sérios questionamentos quanto à vigilância sanitária. Justificam-se os vendedores

(31) Conforme uma investigação realizada em farmácias de Colombo (Sri Lanka) o representante das empresas foi mencionado como fonte prioritária de informação, segundo os entrevistados, seguida das prescrições médicas (WOLFFERS, I. Drug information and sale practices in some pharmacies of Colombo, Sri Lanka. Social Science \& Medicine 25(3):319-21, 1987).

(32) Há noticias de que as comissões oferecidas pelos produtores aos balconistas variam entre 2 e $20 \%$ sobre os preços de venda de determinado medicamento (BARROS, José Augusto Cabral de. Propaganda de medicamentos: Atentado à saúde?, p. 105) e GIOVANNI, G. A questão dos remédios no Brasil - produção e consumo. São Paulo: Polis, 1980.

(33) WOLFFERS I. Op. cit.

(34) Pesquisas realizadas no Brasil. BARROS, J. A. C. A medicalização da diarréia - Um estudo de caso em Recife. Rev. Farm. Bioquim. Univ. Minas Gerais, XI(2):63-71, 1991; e BESTANE, W. J.; MEIRA, A. R.; KRASUCKIM. R.; AUN, R. A.;COELHO,C. S.; CHAZANAS, W.; PÉRI, E. \& SLAWKA, S. Alguns aspectos da prescriçāo de medicamentos para o tratamento de gonorréia em farmácias de Santos. São Paulo: AMB Rev. Assoc. Med. Bras. 26(1): 2-3, 1980. Outra pesquisa similar toi realizada em Bangladesh (TOMSON, G. \& STERKY, G. Self-prescribing by way of pharmacies in three Asian developing countries. Lancet II:620-2, 1986). 
asseverando que comercializam "medicamentos populares". Contudo, como vimos, nenhum medicamento é isento de efeitos indesejáveis; todos eles merecem atenção especial, razão por que se deve combater sua utilização desmedida.

Nesse aspecto, as farmácias têm um papel muito importante no desenvolvimento da assistência à saúde, não podendo exercer, pois, unicamente uma atuação comercial. Devem ser, sim, um forte agente na promoção da saúde e de reeducação para o uso racional de medicamentos. Todavia, para que isso ocorra de forma eficaz, é preciso reformular sua estrutura de representação e função, de forma a tornar sua contribuição mais profícua ao sistema de saúde.

\subsection{A propaganda dirigida aos profissionais da saúde}

O material produzido para essa modalidade de propaganda não só é utilizado como instrumento de informação acerca de um produto mas como meio de atualização dos médicos, uma vez que visam à utilização de formas terapêuticas recentes destinadas aos pacientes.

Vale observar que, em âmbito mundial, a expansão de novas especialidades farmacêuticas, pesquisas, testes de produtos etc. é realizada quase que com total exclusividade pelas grandes empresas ou por institutos de pesquisas vinculados a elas. Por essa razão, a indústria farmacêutica detém e concentra o conhecimento acerca dos medicamentos que cria.

Da mesma forma, a divulgação técnica é realizada e patrocinada pela indústria farmacêutica, e da informação técnica depende o médico, ou seja, a categoria médica restou subordinada às informações das unidades produtoras. É certo que cada médico dispõe de um receituário básico, composto por medicamentos dos quais conhece suas caracteristicas, indicações, contra-indicações etc. $O$ grande intuito das indústrias farmacêuticas é introduzir nesses receituários número cada vez maior de medicamentos. Coube assim ao médico triar as informações fornecidas pela indústria, pairando sobre ele as investidas da publicidade de medicamentos, principalmente dos últimos lançamentos da indústria farmacêutica ${ }^{(35)}$.

Desde a explosão do desenvolvimento da indústria farmacêutica, resultou cada vez mais evidenciado que as informações produzidas e disseminadas pela indústria farmacêutica podem influenciar as prescrições elaboradas por médicos ${ }^{(36)}$. Para divulgar as informações comerciais e técnicas, as

(35) BARROS, José Augusto Cabral de. Propaganda de medicamentos..., cit., p. 88.

(36) HEMMINKI, E. (1988a) Factors influencing prescribing, in: GHODSE, H. \& KHAN (ed.). Psychoactive drugs: improving prescribing practices. Genebra: WHO, pp. 22-35. 
indústrias utilizam-se de diversos instrumentos, desde revistas especializadas, amostras grátis e artigos científicos até a abordagem pessoal por pessoas, assim chamadas "propagandistas", que, ademais de fornecerem o material acima, oferecem brindes, bem como viagens ou convites para congressos aos médicos.

A atividade dos propagandistas, por muitos anos, não foi disciplinada em lei, vindo somente a ser regulada com a Resolução RDC n. 102/2000, editada pela ANVISA. Certamente o principal e mais importante alvo dos propagandistas é o médico, em que pese a grande incidência da prática de automedicação, porquanto realizam inúmeras visitas em consultórios, mantendo constante contato pessoal com o profissional médico. Esse cuidado em vincular o propagandista ao prescritor tornou-se, há muito, um método eficiente e distante de qualquer controle. Um estudo realizado nos EUA, no começo dos anos 60 , buscou verificar as informações transmitidas pelos propagandistas, e concluiu-se que a maioria das informações por eles fornecida não possuía esteio científico, sendo altamente perigosas à saúde públi$\mathrm{Ca}^{(37)}$.

Outros estudos, porém, revelaram que o material fornecido pelos propagandistas foi avaliado pelos médicos como fonte útil de informaçōes sobre medicamentos ${ }^{(38)}$. Essa análise foi realizada na Austrália, nos EUA e no Reino Unido, e demonstrou que o propagandista ocupa o segundo lugar na preferência dos médicos, os quais entenderam ser este um meio seguro de informaçōes. Considera-se, também, que o material fornecido pelos propagandistas serve, ainda, como forma de entrar em contato com os novos lançamentos de produtos farmacológicos ${ }^{(39)}$.

Todavia, para as companhias, o propagandista labora muito mais como "promotor de vendas" do que como divulgador de informações, na medida em que tal método de publicidade tem seu efeito medido pelo aumento das vendas e não pelo conhecimento transmitido ${ }^{(40)}$. Estudos realizados no Rei-

(37) LOBO, F. Estructuras monopolisticas y publicidad: el sistema de desinformación farmacéutica. Revista Española de Investigaciones Sociológicas, 5:81-117, 1979.

(38) Assim se manifestou $42 \%$ de uma amostra aleatória de médicos entrevistados no Tenessee (EUA); $51 \%$ de 453 GP, no Reino Unido; $56 \%$ de 200 médicos canadenses atuantes em programas de medicina de familia; $80 \%$ dos médicos incluidos em uma pesquisa realizada em Nova Jersey (EUA), e $70 \%$ de 284 médicos entrevistados na Nova Zelåndia (LEXCHIN, J. Doctors and detailers: therapeutic education or phermaceutical promotion?, Int. j. health serv 19(4):663-79, 1989).

(39) Os inquéritos realizados no Reino Unido, em 1966, pelo Sainbury Committee e em 1975 pelo Office of Health Economics (instituição criada em 1962 pela associação de produtores com o propósito de realizar investigaçōes sobre os aspectos econơmicos da assistência médica), são coincidentes quanto ao lugar prioritário do propagandista como origem do conhecimento de novos produtos. Já no que respeita à eficácia dos medicamentos, na segunda das pesquisas referidas, a preferência dos GP entrevistados recaiu sobre "artigos em revistas" e "recomendaçāo de colegas". ficando o "representante", neste aspecto, no quinto posto (Smith, 1977).

(40) HEMMINSKI, E. \& Psonen, T. An inquiry into associations between leading physicians and the drug industry. Social Science \& Medicine 11:501-6, 1977. 
no Unido, com dados levantados em entrevistas com propagandistas de 21 empresas, revelam que a grande maioria dos propagandistas (87\%) tem de atingir determinada cota de vendas ${ }^{(41)}$.

Neste quadro, é no mínimo duvidoso o papel do propagandista na divulgação de informações técnicas, posto que a ele são também atribuídas as tarefas de incentivar o consumo do medicamento e incrementar sua venda, donde se dessume sua imparcialidade. Afigura-se-nos que a informação comercial está a substituir a educação acadêmica, e mais grave, que profissionais da saúde estejam na difícil condição de dependência do conteúdo transmitido por propagandistas.

Em alguns países em desenvolvimento é possível encontrar fontes de informação que não aquelas fornecidas pelos fabricantes de medicamentos. Normalmente são os informes de universidades, dos departamentos de saúde pública, das associações profissionais e das organizações de consumidores, dentre outros. Já nos paises subdesenvolvidos, a influência da indústria farmacêutica é muito grande, porque são mínimas as outras fontes de informação.

\subsection{A propaganda direta ao consumidor}

No Brasil, os medicamentos passíveis de divulgação direta ao consumidor são aqueles de venda livre, ou seja, cuja venda não está condicionada à prescrição médica. Há inúmeros instrumentos de propaganda direta ao consumidor, como os tradicionais programas de televisão que precedem ou acompanham o lançamento de novos produtos, as mensagens transmitidas pelo rádio e por anúncios publicitários em farmácias e outdoors, artigos em periódicos e revistas de interesse geral. Dentre as técnicas de publicidade existentes, são muito comuns aquelas que transmitem conteúdos não verbais (desenhos, fotografias etc.). Segundo estudos na área de psicologia, essa forma de mensagem, muitas vezes, promove no seu receptor um impacto muito maior do que as informações verbais propriamente ditas. Para Mackowiak e Gagnon, a propaganda direta ao usuário deverá aumentar no futuro ${ }^{(42)}$, a ponto não encontrar limites na televisão a cabo ou na Internet.

\footnotetext{
(41) Em 1990, outra pesquisa baseada em entrevistas com médicos revelou que, durante o ano em curso, $68 \%$ desses profissionais havia recebido pelo menos uma vez uma visita de um propagandista, na qual perceberam que seus conhecimentos a respeito do produto anunciado eram insuficientes (HAl - Health Action International. Promoting health or pushing drugs? A critical examination of marketing of pharmaceuticals. Amsterdam: HAI Europe, 1992).

(42) MACKOWIAK, J. I. \& GAGNON, J. P. Effects of promotion on pharmaceutical demand. Social Science \& Medicine, 20(11):1,191-7, 1985.
} 
Existe também um fator mais abstrato, mas não menos importante, que é a sensibilização do paciente diante da propaganda de medicamento, induzida pela esperança de cura. Considerando a insuficiência da terapêutica atual e a grande incidência de novas doenças, há o favorecimento da idéia de que o acervo de medicamentos atual carece de novidades e melhorias.

O envolvimento do consumidor na escolha da terapia com medicamentos de venda sob prescrição médica, por sua vez, tende a crescer gradualmente. Isto resulta, em parte, dos esforços da própria indústria, que investe na publicidade direta ao consumidor em muitos países. $O$ número de pacientes que sofrem de doenças crônicas continua a crescer, e eles têm demonstrado conhecer melhor seus medicamentos do que no passado.

No entanto, o interesse do consumidor por maiores informações ${ }^{(43)}$ sobre medicamentos para venda com receita médica vem, inevitavelmente, acompanhado de prejuízos extremos para ele mesmo. Para que o consumidor tenha convicção para decidir qual medicamento é o melhor e o mais recomendável para os efeitos que deseja obter, imprescindivel seria que tivesse conhecimentos profissionais para tanto. Como esta é uma prerrogativa somente daqueles que trabalham na área médica, mister se faz a intermediação, nesta cadeia, de pessoal especializado. Assim, conclui-se que, mesmo que o consumidor tenha conhecimento leigo sobre o medicamento, não se pode subtrair do profissional da área de saúde a sua supremacia, o que o torna insubstituível.

Outro fator preponderantemente negativo quando se trata de publicidade direta ao consumidor é que as informações transmitidas por meio dos veículos de comunicação podem ser apresentados de forma a sugerir diferentes conotações, resultando no conhecimento superficial do produto. Assim sendo, o anúncio cumprirá seu objetivo maior, que é vender o produto, no momento em que o consumidor se satisfizer com as informações obtidas por meio dele, sem que realmente tenha conhecimento de todos os aspectos negativos que envolvem o produto anunciado, que certamente dele foram omitidos.

No entanto, argumentam as empresas que os anúncios de produtos farmacêuticos, como quaisquer outros produtos, tendem a destacar os be-

(43) O Serviço de Medicina Interna do Hospital 12 de Outubro, em Madri, realizou um teste entregando aos pacientes que tiveram alta algumas folhas informativas sobre os medicamentos que estavam utilizando. Foi constatado que os pacientes realmente tinham interesse em obter maiores informaçōes sobre a medicação que utilizam (ESCOBAR, C.R.; PIQUERO, J. M. P.; SANZ, N. M.; GONZÁlES, A. P. Herreros de Tejada dados de alta en el hospital. Atención Primaria, 14(3): 35-9, 1994). 
nefícios e amenizar os malefícios, pois, não fosse assim, ninguém os compraria. Asseveram que o fato de tratar-se de negócio que objetiva obtenção de lucro, como qualquer outro, não significa que, por isso, podem vender produtos perigosos ou ruins. Dai por que entendem que não se pode pôr todo o peso negativo em grandes manchetes ${ }^{(44)}$.

A utilização de publicidade direta ao consumidor (PDC) por indústrias farmacêuticas vem aumentando consideravelmente nos últimos anos, inclusive para medicamentos de venda sob prescrição médica, gerando opiniões bastante divergentes por parte dos profissionais da área de saúde, sobre os benefícios e riscos de sua veiculação.

Esse tipo de publicidade dirigida impõe a apresentação de todos os aspectos do produto, sejam ou não benéficos. Embora exista regulamentação em diversos países para estruturar a propaganda de medicamentos para o consumidor, dificilmente as indústrias apontam as deficiências de seus produtos em anúncios. Tanto é assim que a publicidade voltada ao público consumidor omite contra-indicações, reações adversas e mesmo os cuidados que devem ser tomados na utilização da medicação anunciada. Seu conteúdo também reflete interesses puramente comerciais, revestidos de roupagens técnicas ou convincentes, e se auto-intitulando "fonte de informação".

Dois estudos analisaram a propaganda de medicamentos direta ao consumidor de forma bem abrangente: um deles de autoria de Hemminki e Herxheimer ${ }^{(45)}$, e outro de Griffin e Griffin ${ }^{(46)}$. Advertem os pesquisadores que conseqüências graves podem advir da automedicação sem diagnóstico médico anterior. Uma delas é a confusão, por parte do consumidor, entre os nomes das enfermidades, quando então poderá consumir um medicamento não apropriado ao seu problema. É possivel também que certos medicamentos sejam utilizados por pacientes contra-indicados, em virtude de doença recorrente ou terapia. Hemminki e Herxheimer concluem que "o fornecimento de informações aos consumidores é uma tarefa complexa. Não é somente um problema de distribuir informações independentes e de alta qualidade".

(44) LOBO, F. Op. cit.

(45) Apud GEORGE, Charles F., MD, FRCP. Prof. of Clinical Pharmacology, University of Sou thampton, United Kingdom. Advertising Medicines to the Public. Journal of the Royal College of Physicians of London, vol. 30, n. 2, March/April 1996. HEMMINKI, E. \& HERXHEIMER, A., Journal of The College of Physicians of London, vol. 30, n. 2, March/April 1996, p. 104.

(46) Apud GEORGE, Charles F., MD, FRCP - Prof. of Clinical Pharmacology, University of Southampton, United Kingdom. Advertising Medicines to the Public. Journal of the Royal College of Physicians of London, vol. 30, n. 2, March/April 1996. GRIFFIN and GRIFFIN, Journal of The Royal College of Physicians of London, vol. 30, n. 2, March/April 1996, p. 107. 
Sobre a publicidade direta ao consumidor de produtos de venda sob prescrição médica, a American Society of Health - System Pharmacists $A S H P^{(47)}$, a pedido da FDA, expôs sua opinião e declarou que representa um risco significativo aos pacientes. Isto porque os consumidores são parcialmente informados e pautam-se em expectativas irreais induzidas pelo anúncio. Justifica sua conclusão diante da profundidade de informações e interpretaçōes que se fazem necessárias para o uso apropriado dos medicamentos, o que certamente um anúncio não contempla.

\section{CONSIDERAÇÕES FINAIS}

A saúde, no contexto da população de menor poder aquisitivo, é um meio para o enfrentamento da vida. O medicamento assume, paralelamente com a alimentação, um papel importante para a preservação da capacidade de trabalho, pois proporcionam as condições para que as pessoas possam desenvolver o seu trabalho.

Dai a importância do controle e fiscalização, considerando-se ainda o alto índice de uso desmedido e descurado de medicamentos no País, representando despesas desnecessárias à população. Fato é que os recursos seriam mais bem aproveitados se fossem direcionados para atividades de promoção da saúde e prevenção de doenças ${ }^{(48)}$. Apesar do esforço em obter melhor controle das atividades promocionais da indústria farmacêutica, 0 resultado tem sido insatisfatório no Brasil. Tal problema se verifica até mesmo em países com rigoroso sistema de fiscalização.

Paralelamente temos assistido ao consumo de medicamentos, mesmo ante a possibilidade de outras terapias não farmacológicas, acarretando riscos de graves danos ao paciente. Essa tendência é gerada pela pressão do mercado farmacêutico sobre os profissionais de saúde, que acabam cedendo até mesmo nas situações em que a eficácia do medicamento é incerta, ou então nos casos em que o medicamento não seria a opção mais indicada $^{(49)}$.

Em sua grande maioria, os médicos repudiam as possiveis interterências em sua prescrição, pois não querem ver cerceados seus direitos e liber-

(47) American Society of Health-System Pharmacist comments on direct-10-consumer advertising, Am J Health, vol. 55, Nov. 15 1998, p. 2347.

(48) Referimo-nos aos elevados percentuais de investimentos em marketing farmacêutico, mencionados anteriormente neste estudo, cujos gastos sảo, em última instância, suportados pelo usuário quando adquire o produto.

(49) BARROS, José Augusto Cabral de. Propaganda de medicamentos..., cit., p. 89. 
dade de prescrição. Estudos atestam, contudo, a supremacia da publicidade como fonte de informação e influência, causando fortes direcionamentos nas prescrições médicas, em que pese tal fato não seja admitido expressamente pelos prescritores ${ }^{(50)}$.

A mudança verificada pelos profissionais da área de saúde, após a intensificação da publicidade ao consumidor, pode ser vista no dia-a-dia do serviço público de saúde, quando os médicos passaram a reduzir a anamnese, isto é, a conversa e o exame clínico no paciente, dando maior valor à prescrição e à requisição de exames de laboratório. Resultado disso é a baixa qualidade das consultas, o aumento dos custos e, conseqüentemente, a insatisfação dos pacientes.

É neste quadro em que a consulta médica, ademais de onerosa, tornase insatisfatória, que surgem correntes que defendem a publicidade de medicamentos livre de limitações quando direcionada ao público. Para a defesa dessa hipótese, argumenta-se que, por meio da publicidade, as pessoas têm a possibilidade de detectar, por si mesmas, doenças identificáveis por sintomas específicos ${ }^{(51)}$. Apesar das discussões, os argumentos que sustentam a liberdade de publicidade são inconsistentes, em primeiro porque há doenças cuja identificação é de difícil distinção em relação a outras; em segundo porque poderia o consumidor concluir que sua doença dispensa o acompanhamento médico; em terceiro por não ser a publicidade o meio mais imparcial para informar e esclarecer aos usuários.

As informações essenciais sobre os medicamentos, sem dúvida, não devem se confundir com o caráter comercial da publicidade. A alternativa seria sua publicação por outros meios ${ }^{(52)}$, de caráter independente. Contudo, tais publicações sofreriam as limitações concernentes às fontes de pesquisa e informações, ainda dependentes daquelas produzidas pela indústria farmacêutica, especialmente em países subdesenvolvidos, onde os institutos de pesquisa e universidades enfrentam a forte defasagem tecnológica e científica na área de medicamentos.

A negligência às informações essenciais ao consumidor, por outro lado, abre espaço para a publicidade enganosa e abusiva. Neste quadro pode ocorrer ainda, mesmo diante dos mecanismos de prevenção e de fiscalização que caberia à ANVISA realizar, que da publicidade enganosa ou abusiva de

(50) GOLDSTEIN, J.H. Of mugs and marketing, JAMA 265(18):2391-2, 1991.

(51) MASSON A. \& Rubin, P. H. Matching prescription drugs and consumers - the benefits of direct advertising. N. Engl. j. med 313 (8):513-5, 1985.

(52) Entre as várias iniciativas surgidas na área da informação/educação sobre o uso adequado dos medicamentos e destinados ao público. poderiamos citar os livros Cuidados com os medicamentos, no Brasil, e Santo Remedio! Salud, medicamentos y negocios, no Peru; outros textos foram elaborados para facilitar a tarefa dos agentes comunitários de saúde, como por exemplo: Buscando remedio: Atención básica y uso de medicamentos esenciales. 
medicamentos resulte dano efetivo ao consumidor. Lembra José Geraldo Brito Filomeno que, "no caso de ter havido prejuizo efetivo em decorrência da publicidade falsa ou enganosa, há concurso material de delitos, exatamente porque o que o CDC visa é coibir a fraude publicitária, que coloca em risco a harmonia das relações de consumo"(53).

No campo civil, a consumação do dano enseja a função reparatória, sempre essencial e necessária, ainda que na sua aplicação e no momento da cumprimento do direito não seja atingida plenamente, ou seja, ainda que os danos ocasionados à saúde ou à vida do consumidor não possam ser desfeitos e a condição desse paciente não possa ser reposta no estado anterior ao fato, tal como preconiza o principio da reparação integral(54).

A discussão sobre o dano nos faz, ademais, refletir sobre o fato de as peculiaridades e características dos medicamentes terem ou não repercussão sobre o indenizável. Dissemos, desde o início deste trabalho, que o medicamento apresenta em si mesmo certo grau de nocividade e periculosidade. Essa constatação nos remete à necessidade de sermos conscienciosos, ainda que críticos em relação a essa realidade. Sobretudo, obriga-nos a estabelecer fronteiras claras entre danos admissiveis e danos inaceitáveis, num contexto onde se pretende produzir efeito essencialmente benéfico ao paciente.

Entendemos que cabe ao direito estabelecer a justa medida do dano indenizável, com vistas a restaurar ou minimizar as conseqüências experimentadas pelo consumidor. Isso dependerá contudo de um diálogo profícuo com a ciência farmacêutica. Mas essa é uma indagação que exsurge como reflexão e a qual não temos a pretensão de solucionar neste modesto estudo.

\section{BIBLIOGRAFIA}

AMERICAN SOCIETY OF HEALTH-SYSTEM PHARMACIST: comments on direct-to-consumer advertising, American Journal of Health-System Pharmacist, vol. 55, Nov. 1998.

BARROS, José Augusto Cabral de. Estratégias Mercadológicas da Indústria Farmacêutica e o Consumo de Medicamentos - Revista de Saúde Pública, São Paulo, n. 17, 1983.

$$
\text { . Medicalización y salud. Cuad. Med. Soc. (Ros) (28), } 1984 .
$$

(53) FILOMENO, José Geraldo Brito. O Código de Proteção do Consumidor no Brasil e a regulamentação publicitária: aspectos penais. Revista do Advogado, dez. 1990, n. 33, p. 41.

(54) DIAS, José Aguiar. Da responsabilidade civil. 5 ed. Forense, 1973, p. 87. 
Propaganda de Medicamentos: Atentado à Saúde? São Paulo: Hucitec, 1997.

BAUDRILLARD, Jean. La societé de consommation. Paris: SGPP, 1970.

BENJAMIN, Antonio Herman de Vasconcelos. Uma Introdução ao Código de Defesa do Consumidor. In: LAZZARINI, M.; RIOS, J. O. \& NUNES JR. V. S. Código de Defesa do Consumidor - anotado e exemplificado pelo IDEC. São Paulo: AVS, 1991.

BESTANE, W. J.; MEIRA, A. R.; KRASUCKI, M. R.; AUN, R. A.; COELHO, C. S.; CHAZANAS, W.; PÉRI, E. \& SLAWKA, S. Alguns aspectos da prescrição de medicamentos para o tratamento de gonorréia em farmácias de Santos. São Paulo: AMB-Rev. Assoc. Med. Bras. 26(1): 2-3, 1980.

BITTAR, Carlos Alberto. O Controle da Publicidade no Código de Defesa do Consumidor. São Paulo: Revista dos Tribunais, n. 673, novembro/1991.

CABRAL, Plínio. Propaganda - Técnica da Comunicação Industrial e Comercial. São Paulo: Saraiva, 1993.

CENEVIVA, Walter. Publicidade e Direito do Consumidor. São Paulo: RT, 1991.

COMPARATO, Fábio Konder. Estudos e Pareceres de Direito Empresarial. Rio de Janeiro: Forense, 1999.

DAVIES, D. M. Textbook of adverse reactions. $4^{\text {th }}$ edition. Oxford: Oxford University Press, 1991.

DIAS, José Aguiar. Da responsabilidade civil. $5^{\mathbf{a}}$ ed. Rio de Janeiro: Forense, 1973.

ESCOBAR, C. R.; PIQUERO, J. M. P.; SANZ, N. M.; GONZÁles, A. P. Herreros de Tejada dados de alta en el hospital. Atención Primaria, 14(3), 1994.

FILOMENO, José Geraldo Brito. O Código de Proteção do Consumidor no Brasil e a regulamentaçāo publicitária: aspectos penais. Revista do Advogado, n. 33, dez./1990.

GEORGE, Charles F., MD, FRCP - Prof. of Clinical Pharmacology, University of Southampton, United Kingdom. Advertising Medicines to the Public. Journal of the Royal College of Physicians of London, vol. 30. n. 2, March/ April 1996.

GIOVANNI, Geraldo. A Questão dos Remédios no Brasil - produção e consumo. Coleção Sociologia e Saúde, vol. 1. São Paulo: Polis, 1980.

GOLDSTEIN, J. H. Of mugs and marketing, JAMA 265(18), 1991.

GOODMAN and GILMAN, Alfred et al. As Bases Farmacológicas da Terapêutica. $8^{2}$ ed. Rio de Janeiro: Guanabara Koogan, 1991. 
HAl (Health Action International) - IFPMA (International Federation of Pharmaceutical Manufactures Associations). Code of pharmaceutical marketing pratices. An international code of pharmaceutical marketing practices - a discussion document.

HEMMINKI, E. Factors influencing prescribing, in: GHODSE, H. \& KHAN (ed.). Psychoactive drugs: improving prescribing practices. Genebra: WHO. 1988.

\& PSONEN, T. An inquiry into associations between leading physicians and the drug industry. Social Science \& Medicine 11, 1977.

LEXCHIN, J. Doctors and detailers: Therapeutic education or pharmaceutical promotion? Int. Journal Health Serv. 19(4), 1989.

LOBO, F. Estructuras monopolisticas y publicidad: el sistema de desinformación farmacéutica. Revista Española de Investigaciones Sociológicas, n. 5, 1979.

MACKOWIAK, J. I. \& GAGNON, J. P. Effects of promotion on pharmaceutical demand. Social Science \& Medicine, 20(11), 1985.

MASSON A. \& Rubin P. H. Matching prescription drugs and consumers - the benefits of direct advertising. New England Journal of Medicine, 313 (8), 1985.

MEDAWAR, C. Power and dependence - social audit on the safety of medicines. Londres, Social Audit, 1992.

NIES, Alan S. "Princípios da Terapêutica". In: GOODMAN and GILMAN, AIfred et al. As Bases Farmacológicas da Terapêutica. Rio de Janeiro: Guanabara Koogan, 8ª ed., 1991.

QUEIROZ, M. S. O paradigma mecanicista da medicina ocidental: uma perspectiva antropológica. Rev. Saúde Pública, n. 20, 1986.

ROZENFELD, S. \& PORTO, M. A. T. "Vigilância Sanitária: uma abordagem ecológica da tecnologia em saúde". In: Saúde, ambiente e desenvolvimento. Rio de Janeiro: Hucitec/Abrasco.

SATO, Miriam Keiko de Souza. Propaganda e Publicidade de Medicamentos no Direito Civil (Dissertação de Mestrado) - Faculdade de Direito da Universidade de São Paulo, 2002.

SINDICATO DA INDÚSTRIA DE PRODUTOS FARMACÊUTICOS NO ES. TADO DE SÃO PAULO, Farmacovigilância - Manual de Implementação. São Paulo: SINDUSFARM, 1995.

SMITH, Mickey C. Ph.D., Pharmaceutical Marketing - Strategies and Cases. New York: The Haworth Press, 1991. 
SZUBA, T. J. Drug promotion under the magnifying glass. J. Soc. Adm. Pharm. 4 (2), 1987.

TAYLOR, R. Medicine out of Control - the anatomy of a malignant technology. Melbourne: Sun Books, 1979.

TEMPORÃO, José Gomes. A propaganda dos medicamentos e o mito da saúde. Rio de Janeiro: Graal, 1986.

TOMSON, G. \& STERKY G. Self-prescribing by way of pharmacies in three asian developing countries. Lancet. II, 1986.

WOLFFERS, I. Drug information and sale practices in some pharmacies of Colombo, Sri Lanka. Social Science \& Medicine, 25(3), 1987.

WORLD HEALTH ORGANIZATION (WHO), document A35/7. 